\title{
Análisis normativo-institucional de los espacios verdes públicos ribereños en el Área Metropolitana de Neuquén (Argentina)
}

\section{Normative-institutional analysis of riverside public green space in the Neuquén Metropolitan Area (Argentina)}

\author{
Micaela López \\ Profesora. Universidad de las Flores. Buenos Aires, Argentina. \\ mica_cip@yahoo.com.ar |0000-0002-4276-8216 \\ Jorge Gentili \\ Profesor. Universidad Nacional del Sur. Bahía Blanca. Buenos Aires, Argentina. \\ jogentili@uns.edu.ar $\mid \underline{0000-0002-4787-4667}$
}

Para citar este artículo: López, M., y Gentili, J. (2020). Análisis normativo-institucional de los espacios verdes públicos ribereños en el Área Metropolitana de Neuquén (Argentina). Entorno Geográfico, (20), 42-67. https://doi.org/10.25100/eg.v0i20.10638

\begin{abstract}
Resumen
Los frentes de agua (waterfront en terminología inglesa) responden a una categoría emergente de espacio público. En el Área Metropolitana de Neuquén (Argentina) durante los últimos 10 años se ha promovido una región de cara al río. El objetivo del trabajo es analizar comparativamente el marco normativoinstitucional que rige los espacios públicos verdes ribereños asentados en el tramo inferior del río Limay, en las ciudades de Neuquén y Plottier, con base en una metodología cualitativa de recolección de datos no obstrusivos en documentos y registros en archivos públicos. El análisis se realizó en torno a 4 ejes, jurisdicción de los espacios verdes, marco normativo-institucional de Ordenamiento Territorial Ambiental, planificación hídrica y Ordenamiento Territorial de Bosques Nativos. A nivel
\end{abstract}

local se observó, por un lado, la necesidad de una mayor articulación entre instituciones de diversas jurisdicciones y ámbitos de acción, y por el otro, que la calidad de los espacios verdes no responde a criterios normativos cuantitativos sino cualitativos. A nivel general, resulta fundamental re-pensar las formas de gestionar los espacios verdes de una visión sistémica, y para tal fin, identificar y definir para cada región específica los ejes de abordaje adecuados.

Palabras clave: Espacios verdes públicos ribereños; Bosques ribereños; Ordenamiento Territorial Ambiental; Neuquén; Plottier.

\section{Abstract}

The waterfronts respond to an emerging category of public space. In the Neuquén 
Metropolitan Area (Argentina), for the last 10 years, a region facing the river has been promoted. The objective of the work is to comparatively analyze the normative-institutional framework that governs the green public riparian spaces located in the lower section of the Limay river, in the cities of Neuquén and Plottier, based on a qualitative methodology for collecting nonobstrusive data in documents and records in public files. The analysis was carried out around 4 axes, jurisdiction of green spaces, normative-institutional framework of territorial environmental ordering, water planning and territorial ordering of native forests. At the local

Recibido: 15 de abril de 2020

\section{Introducción}

Uno de los elementos más importantes de una metrópolis son los espacios públicos en los que se materializan las relaciones entre los habitantes (Borja y Muxí, 2003). En el marco del Objetivo para el Desarrollo Sostenible No. 11 de la Agenda 2030, elaborada por la Organización de las Naciones Unidas (ONU) (United Nations General Assembly, 2015), se desprende de una de sus metas la necesidad de incrementar el espacio público y el espacio verde público, de acceso universal, seguro e inclusivo, con el fin de desarrollar ciudades y comunidades sostenibles, resilientes y seguras.

En un contexto de revalorización de los lugares, como forma de diferenciación y competencia territorial (Nogué, 2006), el reposicionamiento de los espacios level, it was observed, on the one hand, the need for greater coordination between institutions from different jurisdictions and spheres of action, and on the other, that the quality of green spaces does not respond to quantitative but rather qualitative normative criteria. At a general level, it is essential to rethink the ways of managing green spaces from a systemic vision, and for this purpose, identify and define for each specific region the appropriate approach axes.

Keywords: Riverside public green space, Riparian forests; Urban environmental planning; Neuquén; Plottier

Aceptado: 27 de julio del 2020

verdes públicos en las ciudades implica una necesaria intervención institucional a través de políticas públicas con el fin de gestionar y garantizar la sustentabilidad de éstos (Chavoya Gama, 2013). En este sentido, diversos autores han definido sistemas de índices e indicadores para valorar la sustentabilidad de los espacios urbanos y verdes. Entre ellos se encuentran una serie de indicadores relacionados a la dimensión política, el marco normativoinstitucional, los planes de ordenamiento territorial, la gobernanza integral y la cooperación interinstitucional (García y Guerrero, 2006; Salina Chávez et al., 2008; Pinzón Botero y Echeverri Álvarez, 2012; Castillo, 2013; Lozano Leal et al., 2016).

Existe a nivel internacional una tendencia por revalorizar los cuerpos de 
agua y recuperar las costas (Talesnky y Gutiérrez, 2002; Pavia, 2011; Gastaldi y Camerin, 2015; Orellana et al., 2016). En este contexto, los frentes de agua (waterfront), como estrategias innovadoras de desarrollo urbano, resultan en una intervención tanto sobre la costa como sobre el conjunto de la ciudad (Garriz y Schroeder, 2016), propiciando cambios en la estructura urbana y su dinámica. Estos espacios crean lugares de actividades diversas donde antes no existían y "...responden a una categoría emergente de espacio público." (Talesnik y Gutierrez, 2002, p. 23, citado en Garriz y Schroeder, 2016, p. 24). En este sentido, en el Área Metropolitana de Neuquén (AMN) (Programa de Desarrollo de Áreas Metropolitanas del Interior (DAMI), 2014) en los últimos 20 años se ha promovido desde el estado local construir una región de cara al río, lo que ha generado intervenciones en obras civiles de distinta envergadura. En la metrópolis neuquina los espacios costeros no sólo son considerados como espacios públicos, sino como espacios estratégicos para insertarse en el mundo globalizado (Converti y De Marco, 2007; Boggi y López, 2019).

Los cambios producidos en los procesos de urbanización del Área Metropolitana de Neuquén modificaron los espacios naturales existentes, creando un paisaje urbano expandido y espacios propicios para la generación de situaciones de riesgo y de desastres (Porco, 2017). A su vez, la evolución en los cambios de usos del suelo sobre la costa ribereña del río Limay implicó el avance del suelo urbano sobre humedales y bosques ribereños, sistemas naturales caracterizados por una importante dinámica ambiental (fluvial, climática, ecosistémica). En virtud de ello, resulta primordial el manejo de los espacios que se extienden sobre los humedales del AMN.

Los proyectos de recuperación y regeneración de espacios costeros implican la concatenación de decisiones complejas en torno a la gestión urbana, que involucran tanto a instituciones públicas como a actores privados de diversos niveles jerárquicos (Banco Interamericano de Desarrollo, 2015). Ejemplos de ello son los casos de la ciudad de Rosario (Santa Fe, Argentina) y la recuperación del frente costero del río Paraná (ibíd), de las localidades de Quilmes, Avellaneda y Vicente López (Buenos Aires, Argentina) sobre las costas del río de la Plata (Wertheimer, 2018), de Comodoro Rivadavia (Chubut, Argentina) en la costa atlántica (Raimondo, 2010 ), la provincia de Málaga (España) y su espacio litoral (Galacho Jiménez, 2002), la localidad de Cancún (México) y su proyecto gubernamental de cara a la costa (Sosa Ferreira y Jiménez Martínez, 2012). Puntualmente, los espacios verdes públicos del AMN abordados en éste artículo representan una categoría de análisis compleja, en tanto se constituyen como elementos urbanos fundamentales, pero se asientan sobre un sector costero o litoral, y simultáneamente, sobre bosque ripario. En este contexto, cabe preguntarse: ¿Cuál es el marco normativo que rige para los espacios públicos verdes en las costas del río Limay? ¿Cómo es la posición de los bosques riparios dentro del ordenamiento territorial de bosques 
nativos? ¿De qué manera la planificación territorial incorpora la dinámica hídrica? ¿Qué actores institucionales se encuentran implicados en su manejo? En tal sentido, el objetivo del trabajo es analizar comparativamente el marco normativo-institucional derogado y vigente que rigió y rige los espacios verdes públicos ubicados sobre las costas ribereñas del tramo inferior del río Limay, en las ciudades de Plottier y

\section{2. Área de estudio}

\section{El bosque ribereño en el AMN: evolución hacia espacios verdes públicos multiuso}

Regionalmente, el área de estudio está asentada en la región biogeográfica del Monte (Morello, 1995), caracterizada por un clima árido y semiárido. Sin embargo, la costa ribereña del río Limay, en el tramo abordado, representa una isla biogeográfica con características de corredor fluvial y desarrollo de masas forestales de salicáceas y cercos verdes (Lopez et al., 2019). El bosque ripario se caracteriza por la presencia de diversas especies vegetales asociadas a las geoformas modeladas por el río (Datri y Maddio, 2010).

Históricamente, los cuerpos de agua representaron ejes estructurantes del territorio en el AMN. En sus inicios, posibilitaron la consolidación de una matriz productiva frutícola y posteriormente la producción energética a raíz de la construcción de represas hidroeléctricas (Bendini y Steimbreger, 2007; Landriscini et al., 2014; Pérez, 2018). Recientemente, en las últimas dos
Neuquén. Se espera, con base en ello, que el presente artículo pueda ser utilizado para el análisis normativoinstitucional integral de categorías similares de espacios verdes públicos $\mathrm{y}$, por lo tanto, contribuir a su gestión, tanto en el AMN como en otras urbanizaciones donde sus emplazamientos posean características semejantes.

décadas, la intervención del bosque ribereño dio nacimiento a un polo comercial, turístico e inmobiliario, asociado a proyectos de renovación urbana caracterizados por el desarrollo de espacios verdes multiusos.

\section{Los espacios verdes públicos ribereños en el AMN: Unidades de análisis}

El área de estudio comprende la costa ribereña del río Limay, desde la ciudad de Plottier hasta su confluencia con el río Neuquén. El universo de análisis está compuesto por espacios verdes públicos del Área Metropolitana de Neuquén ubicados sobre la margen norte del río Limay. La selección de las unidades de análisis responde a muestras diversas de tipo no probabilísticas (Hernández Sampieri et al., 2014), con el fin de identificar similitudes y diferencias en el régimen normativo-institucional de los distintos espacios verdes públicos ribereños en el AMN. Puntualmente, las unidades de análisis (Figura 1) se componen de tres espacios verdes públicos ubicados en la ciudad de Neuquén y dos en la ciudad de Plottier. 
Fuente: Elaboración propia.

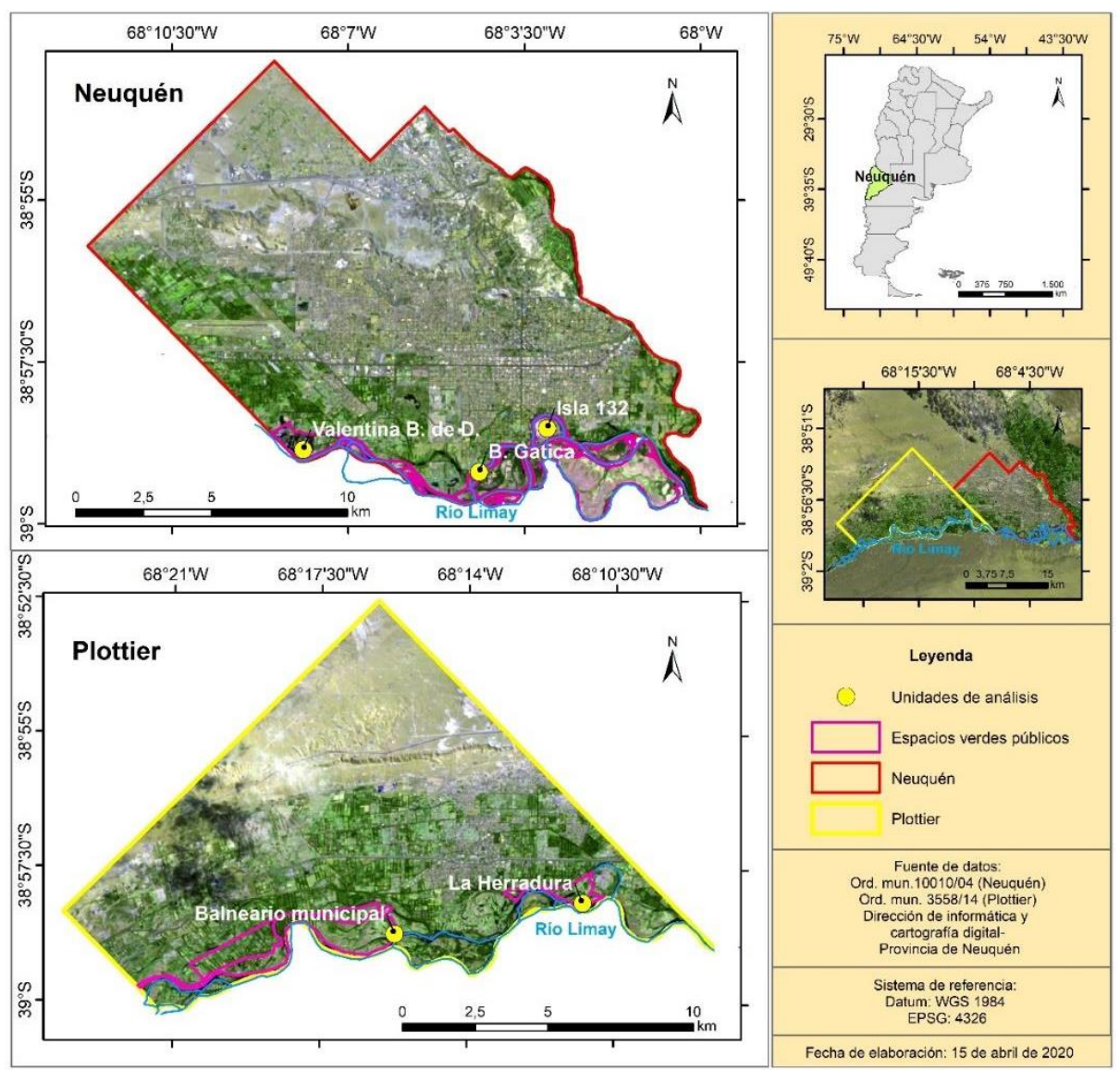

Figura 1. Unidades de análisis sobre la costa ribereña del río Limay.

Los primeros espacios verdes sobre la costa del río Limay surgieron de forma espontánea como balnearios públicos usados por la población (Dirección General de Arquitectura y Urbanismo, 1992). En la actualidad se pueden reconocer dos grandes proyectos:

-El proyecto Ribera Urbana-Zona de Gestión Especial Paseo de la Costa, que une los balnearios Río Grande y Sandra Canale. Dos unidades de análisis se encuentran dentro de esta zona y corresponden a los distritos "Isla 132" y "Balnearios". Cada distrito posee directrices urbanas determinadas, estando la zona de "Balnearios" destinada principalmente a uso recreacional, mientras que la "Isla 132" agrupa una gran diversidad de usos del suelo.

-El proyecto Paseo Costanero, que une las márgenes de los ríos Limay (entre la calle Futaleufú hasta la Confluencia) y Neuquén (desde la Confluencia hasta el límite Norte del Barrio Rincón de Emilio -sector Ameban). La unidad de análisis Valentina Brun De Duclout se encuentra dentro de plan Paseo Costanero, pero no forma parte de la Zona de Gestión Especial.

De forma similar, en la ciudad de Plottier los primeros espacios públicos verdes surgieron de forma espontánea $\mathrm{y}$ actualmente cuenta con 2 grandes áreas que abarcan la "zona ribereña e islas": 
"La Herradura" y el "Balneario Municipal".

\section{Metodología}

Los espacios verdes públicos abordados se han constituido en espacios multiusos. En este sentido, para Maldonado Saravino (2016, p. 41), "la multifuncionalidad, corresponde tanto a conceptualizaciones, nociones y modos de construir y producir en relación a una perspectiva objetiva y funcional del espacio". Desde la perspectiva materialista de territorio de Haesbaert (2011, citado en Maldonado Saravino, 2016), la dominación estatal y empresarial se vincula a la funcionalidad del territorio, se concibe desde campos como la planificación, el urbanismo o el ordenamiento de territorios (Lefebvre, 1983, citado en Maldonado Saravino, 2016) y se efectiviza a través de marcos normativos e institucionales. En este sentido, desde la Geografía Política existe una línea creciente de trabajo interesada en las políticas y sistemas de gestión ambiental a diversas escalas jurisdiccionales (Quintero, 2007). Con base en lo anterior, la geografía de la gobernanza se constituye como una metodología adecuada para abordar al espacio verde desde esta dimensión, en la medida que considera, de manera simultánea, la diversidad y relaciones entre espacios, así como también las interdependencias e interrelación de las escalas espaciales e institucionales (Glückler et al., 2019).

El presente artículo se desarrolló con base en la metodología planteada por Hernández Sampieri et al. (2014), que proponen, desde un enfoque cualitativo, la recolección de datos no obstrusivos en torno a la revisión de documentos y registros en archivos públicos. La revisión de la literatura se realizó en relación a 4 ejes que rigen a los espacios verdes públicos bajo análisis (Figura 2), la jurisdicción de los espacios verdes, el marco normativo de Ordenamiento Territorial Ambiental de las localidades de Neuquén y Plottier, la planificación hídrica y el Ordenamiento Territorial de Bosques Nativos (OTBN). Puesto que los espacios verdes son elementos constitutivos de las ciudades, los dos primeros ejes seleccionados se relacionan con las instituciones que tienen jurisdicción sobre ellos y el ordenamiento territorial existente en las ciudades. A su vez, dadas las características particulares de las áreas de emplazamiento de las unidades de análisis, se consideró la importancia de abordar la planificación hídrica y el OTBN. 
Figura 2. Metodología de análisis de marco normativo.

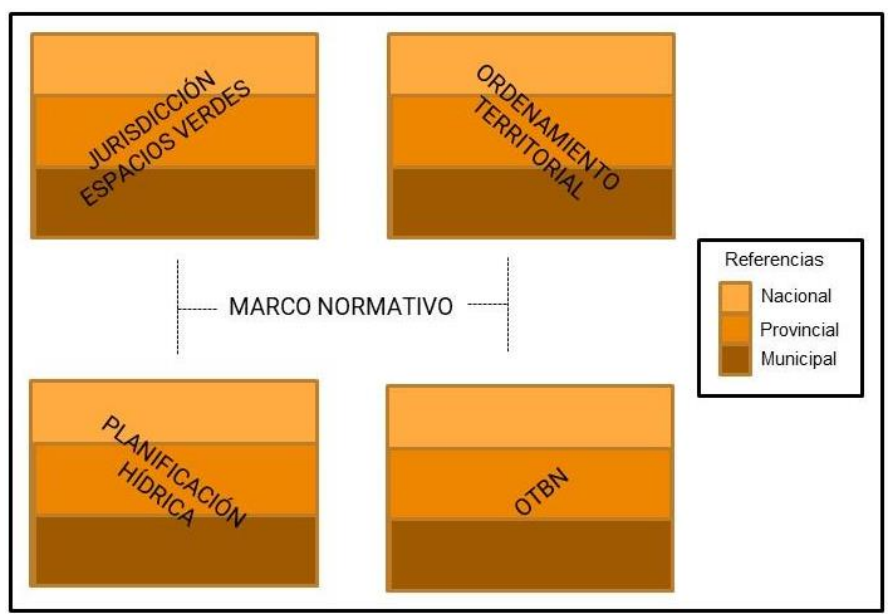

Fuente: Elaboración propia.

La revisión abarcó, tanto, artículos sobre políticas asociada a proyectos de renovación urbana a nivel internacional y nacional, así como una revisión normativa-institucional, regional y local, de tipo descriptiva. La finalidad fue recoger información acerca de la normativa derogada y vigente respecto a los espacios verdes públicos en ambientes ribereños a diferentes niveles administrativos e identificar el marco institucional que los regula. Para tal fin se llevó a cabo un relevamiento de documentos en repositorios virtuales y en el archivo histórico municipal de la ciudad de Neuquén. De la misma forma, se realizó una entrevista no estructurada (Hernández Sampieri et al., 2014), en relación con el OTBN, a un actor académico dedicado a la temática de bosques ribereños de la región.

La información recolectada se organizó en dos apartados. En el primero se desarrolló el marco normativo de los espacios verdes públicos ribereños. En el segundo apartado se identificaron los actores institucionales claves involucrados en la gestión de los mismos. Para tal fin se elaboró un mapa de instituciones vinculadas a la gestión de los espacios verdes según la propuesta de Tapella (2007), que con base en el Mapeo de Actores Claves (MAC), permitió representar la información recolectada en función de dimensiones espaciales e institucionales. Finalmente, se realizó un análisis comparativo crítico entre los marcos normativo-institucional de los municipios de Neuquén y Plottier.

\section{Marco normativo de los espacios verdes públicos ribereños}

A continuación, se presenta la información en torno al marco normativo que rige a los espacios verdes públicos ribereños. La misma fue recabada a través de la revisión de la normativa vigente y derogada a diferentes niveles administrativos (nacional, regional, provincial y municipal). El apartado está organizado en función de los 4 ejes de análisis propuestos: (1) Jurisdicción de los espacios verdes, (2) Abordaje de los espacios verdes en los planes de Ordenamiento Territorial Ambiental de las ciudades de Neuquén y Plottier, (3) Relación entre los usos del bosque ribereño y la planificación hídrica en el ordenamiento territorial, puntualmente 
en materia de línea de ribera, y (4) El Ordenamiento Territorial de Bosques Nativos (OTBN).

\section{Eje 1: De la jurisdicción de espacios verdes en el área metropolitana de Neuquén}

Los espacios verdes abordados en el artículo se encuentran ubicados sobre zonas ribereñas e islas. La reforma de la Constitución Nacional Argentina en el año 1994 incorporó la federalización de los recursos naturales (Art. 124), estableciendo que les corresponde a las provincias el dominio originario de los recursos naturales existentes en su territorio.

La provincia de Neuquén, a través de la Constitución Provincial (Art. 102) y la Ley provincial No. 263 de 2003 (o Ley de Código de Tierras Fiscales, T.O. 669) reivindicó su derecho sobre los recursos naturales y determinó que los bosques e islas son de dominio fiscal provincial. Sin embargo, mediante la Ley provincial No. 2420 de 2002 desafectó del dominio público la totalidad de los inmuebles identificados como espacios verdes que se encuentran ubicados en jurisdicción de ejidos municipales y los transfirió a los respectivos municipios. Respecto a ello, la ordenanza municipal de Neuquén $\mathrm{N}^{\circ} 8201$ de 1998 (o Código de Planeamiento y Gestión Urbano Ambiental), Texto Ordenado de 2007 (Bloque Temático $\mathrm{N}^{\circ} 1$, Usos y Ocupación del suelo) define que la zona "Parque ribereño", correspondiente al área periurbana de la ciudad de Neuquén, comprende costas, balnearios e islas y constituyen espacios verdes $\mathrm{y}$ recreativos del ejido. Con ello, los espacios públicos verdes, el bosque ripario y las islas pasan a ser de dominio municipal. No obstante, en el año 2000 (ordenanza municipal $N^{\circ} 8976$ de 2000 y su modificatoria 10702 de 2006) se creó la Corporación de Desarrollo Integral de Neuquén Sociedad del Estado (Cordineu S.E.) constituida por la provincia y la municipalidad de Neuquén, a la cual se le cedió, previa desafectación del dominio público e incorporación al dominio privado del Estado municipal a Cordineu S.E., una fracción de tierra de la isla 132.

Por su parte, la ciudad de Plottier en su Código de Planeamiento Urbano Rural (ordenanza municipal $N^{\circ} 3558$ de 2014) define que los espacios verdes están sujetos a los objetivos y necesidades de ordenamiento territorial, siendo facultad de la autoridad municipal su jurisdicción. Asimismo, define en la zonificación del ejido, dentro de la zona rural y extraurbana, la "zona ribereña e islas", cuyas características se desarrollan en el próximo eje.

\section{Eje 2: Marco normativo del Ordenamiento Territorial Ambiental}

Dentro del medio físico urbano, el sistema de espacio público constituye un hito importante en el crecimiento y desarrollo de la ciudad en la medida en que estructura otros componentes físicos y la infraestructura urbana. Adquiere una importancia singular en el ordenamiento físico porque vincula, une, liga, articula espacios con funcionalidades diversas (Ceballos Guerra, 2013).

La Ley General del Ambiente $N^{\circ} 25675$ de 2002, cuya autoridad de aplicación es el Ministerio de Ambiente y Desarrollo Sustentable, establece al ordenamiento 
ambiental del territorio como un instrumento de política y gestión ambiental, que permitirá desarrollar la estructura de funcionamiento global del territorio de la Nación, mediante el trabajo interjurisdiccional integral entre los municipios y las provincias, y de éstas y la ciudad de Buenos Aires con la Nación, a través de un órgano de coordinación ambiental nacional, el Consejo Federal de Medio Ambiente (COFEMA). En este sentido, la Ley Provincial de Ambiente (Ley $\mathrm{N}^{\circ} 1875$, T.O. 2267 de 1998, autoridad de aplicación Subsecretaria de Ambiente de la Secretaria de Desarrollo Territorial y Ambiente) establece al ordenamiento ambiental como instrumento de gestión ambiental.

No obstante, si bien existen a nivel nacional bases para una agenda nacional de planificación territorial (Sociedad Argentina de Planificación Territorial, 2019), así como a nivel provincial un Plan Quinquenal Provincial elaborado por el órgano de planificación territorial provincial, la Secretaria de Planificación y Acción para el Desarrollo (COPADE, 2019), que proponen las promulgaciones de leyes de ordenamiento ambiental territorial nacional y provincial respectivamente, las únicas normativas vigentes en relación a la temática en la actualidad son la Ley Nacional $N^{\circ} 26331$ de 2007 de Presupuestos Mínimos de Protección de los Bosques Nativos y la Ley Provincial N ${ }^{\circ} 2780$ de 2011 de Ordenamiento Territorial de los Bosques Nativos, que serán abordadas en el eje $\mathrm{N}^{\circ} 4$.

\section{La ciudad de Neuquén}

A nivel municipal, en cambio, Neuquén cuenta con un amplio historial en materia de planeamiento urbano. En la línea del tiempo que se presente en la Figura 3, se materializan las normativas derogadas y vigentes respecto a los espacios públicos sobre las costas ribereñas del río Limay desde el ordenamiento territorial de la ciudad. En el análisis de la evolución histórica se identificaron y delimitaron tres etapas en relación con la consideración de los espacios verdes públicos ribereños en el ordenamiento territorial:

Etapa 1: Los espacios verdes costeros no se consideran en el ordenamiento territorial.

Etapa 2: Los espacios verdes costeros se incorporan a la planificación del ejido como áreas de esparcimiento y reserva.

Etapa 3: Diversificación de los usos del suelo en los espacios verdes públicos sobre la costa. 
Fuente: elaboración propia.

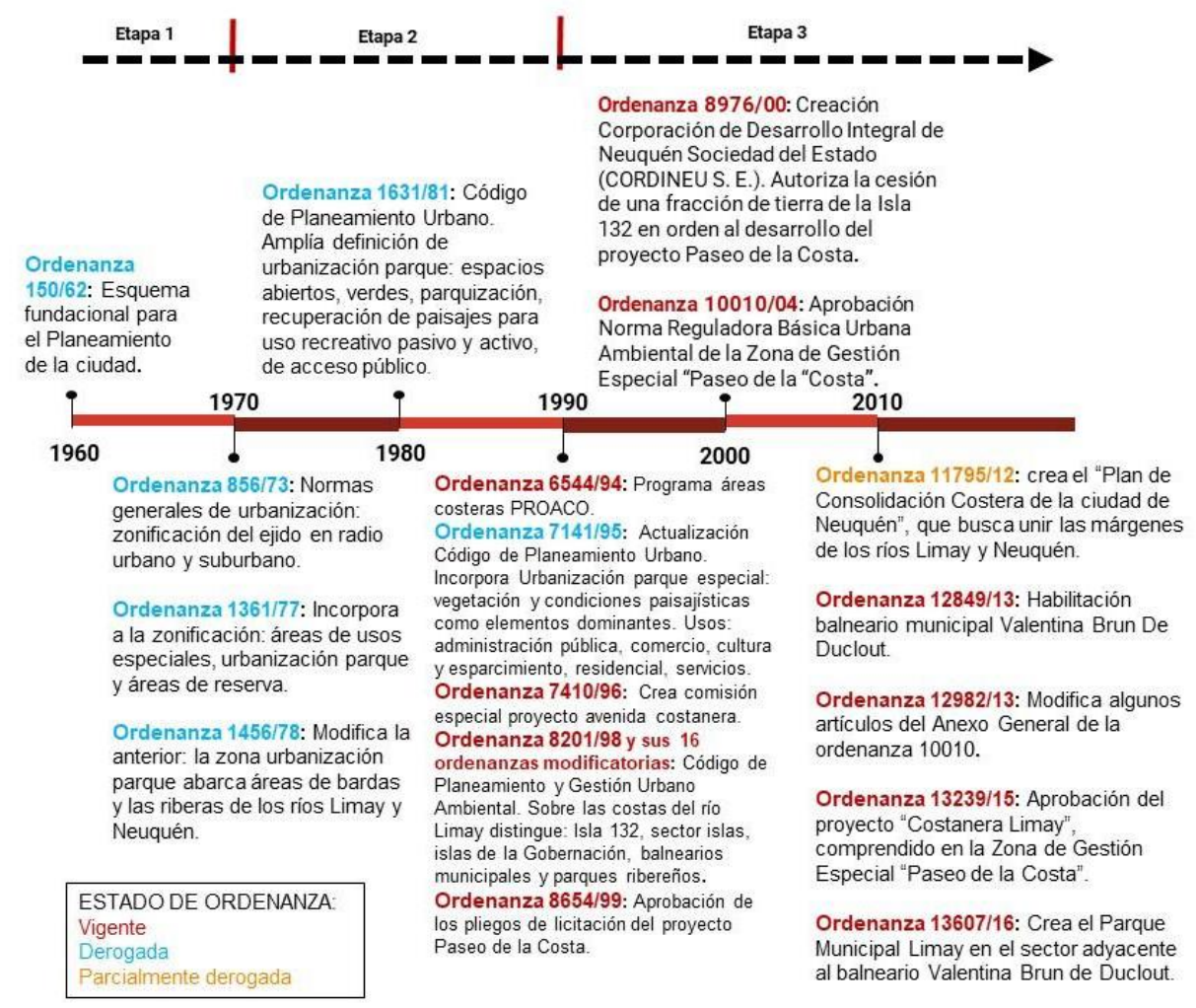

Figura 3. Evolución de los espacios verdes públicos ribereños en el ordenamiento territorial (margen superior). Estados de Ordenanzas promulgadas en la ciudad de Neuquén, en relación con los espacios públicos verdes en ambientes ribereños (margen inferior).

En la ciudad de Neuquén, los espacios verdes públicos sobre la costa del río Limay pueden distinguirse, según se encuentren asentados dentro o fuera de la zona General de Gestión Especial "Paseo de la Costa". De las unidades de análisis abordadas, la Isla 132 y el balneario Gatica se hallan contenidas dentro de esta zona. El principal objetivo del Código de Planeamiento y Gestión Urbano Ambiental de la ciudad de Neuquén es el de: "proponer un nuevo ordenamiento que asegure mayores grados de libertad urbanística y arquitectónica, cuando los proyectos aportan una calidad destacada en la construcción humana del territorio" (ord. No. 10010 de 2004). Para tal fin crea
"Nuevos Instrumentos de Planeamiento", entre los que se encuentran las “Áreas Especiales”. Entre ellas, la Zona de Gestión Especial denominada "Paseo de la Costa" (regulada por las ordenanzas 10010 de 2004 y su ordenanza municipal modificatoria 12982 de 2014, integradas al Bloque Temático $\mathrm{N}^{\circ} 1$ de Usos y Ocupación del Suelo del Código de Planeamiento y Gestión Urbano Ambiental) comprende las costas y áreas colindantes a las costas de los ríos Limay y Neuquén, y alcanza diversos usos de suelo y objetivos.

Posteriormente, en el año 2012 se creó el "Plan de Consolidación Costera de la Ciudad de Neuquén" (ordenanza 
municipal 11795 de 2012). En este contexto, y dado un incremento en la densidad poblacional en el sector adyacente al barrio Valentina Sur Rural que aumentó la demanda de espacios recreativos en esa área, se habilitó el Balneario Municipal "Valentina Brun De Duclout" (ordenanzas municipales 12849 de 2013 y 13587 de 2016), ubicado el sector costero del río Limay

\section{La ciudad de Plottier}

La evolución temporal de las normativas derogadas y vigentes respecto a los espacios ribereños sobre el río Limay en la ciudad de Plottier se presenta en la Figura 4. El nuevo Código de Planeamiento Urbano Rural (ordenanza municipal 3558 de 2014) define dentro de la zona rural y extraurbana sectores que poseen diferente carácter de acuerdo al uso de suelo predominante, y requieren de un análisis diferente al en las adyacencias de la calle Futaleufú, en intersección con el puente Rincón Las Perlas. Este parque ribereño está destinado a uso recreacional y balneario. A su vez, en el año 2016, se creó el Parque Municipal Limay (ordenanza municipal 13607 de 2016), aledaño al balneario que se destinará a uso exclusivo de recreación, esparcimiento, camping municipal y paseo costero.

aplicado en las zonas urbanas, la zona ribereña e islas (ZR9). Si bien la ordenanza establece la preservación de los atributos paisajísticos y ecológicos de la zona ribereña e islas, no especifica cuáles son las medidas o tareas para lograr dichos objetivos. Además, estos principios se contradicen con ordenanzas anteriores que aprueban usos de suelo residenciales en las áreas de protección especial, como puede observarse en la Figura 5.

Fuente: elaboración propia.

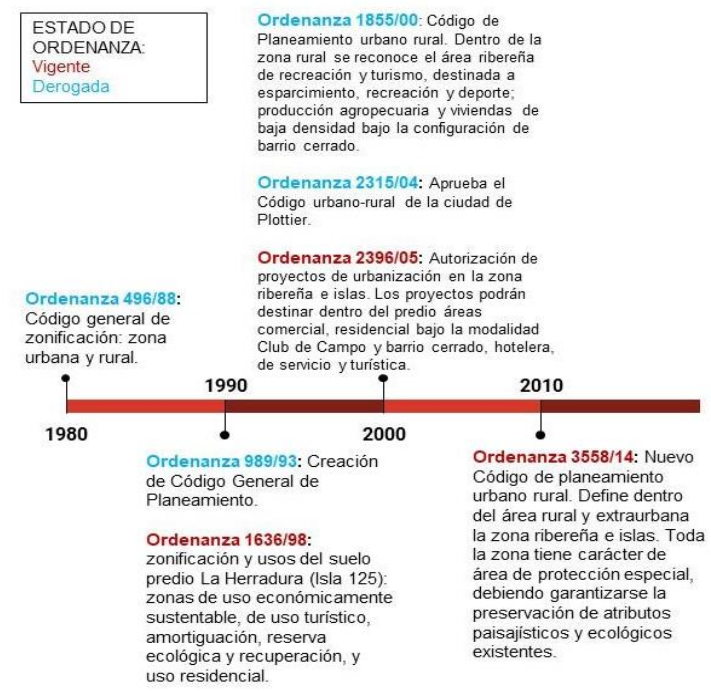

Figura 4. Ordenanzas promulgadas (derogadas y vigentes) en la ciudad de Plottier, en relación a la planificación territorial y los espacios públicos verdes en ambientes ribereños. 
Fuente: elaboración propia.

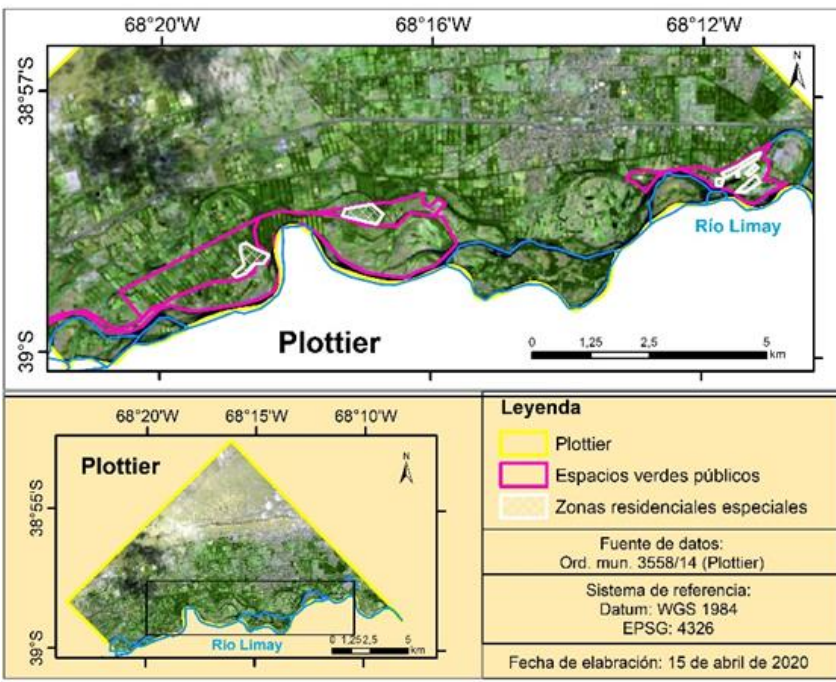

Figura 5. Zonas residenciales especiales en la Zona ribereña y de islas (ZR9) del ejido de Plottier.

En la Tabla 1 se esbozan las principales directrices de las tres ordenanzas que rigen los espacios verdes públicos abordados. En la ciudad de Neuquén, la ordenanza 10010 de 2004 que regula las unidades de análisis Isla 132 y balneario Gatica y la ordenanza 11795 de 2012 que gestiona al paseo costero y al balneario Valentina Brun De Duclout. En la ciudad de Plottier la ordenanza 3558 de 2014.

Tabla 1. Resumen de las principales directrices de las ordenanzas municipales que rigen los espacios verdes públicos bajo análisis.

\begin{tabular}{|c|c|c|c|}
\hline Municipio & \multicolumn{2}{|c|}{ Neuquén } & Plottier \\
\hline $\begin{array}{l}\text { Ordenanza } \\
\text { municipal }\end{array}$ & 10010 de 2004 & 11795 de 2012 & 3558 de 2014 \\
\hline Objetivo & $\begin{array}{l}\text {-Elaborar un } \\
\text { coordinado de } \\
\text { crear } \\
\text { localizaciones } \\
\text { nuevas }\end{array}$ & $\begin{array}{lr}\text { Ejecutar un } & \text { paseo } \\
\text { costanero } & \text { que } \\
\text { permita el tránsito } \\
\text { vehicular } \\
\text { peatonal y/o } \\
\text { espacios públicos } \\
\text { destinados a fines } \\
\text { turísticos. }\end{array}$ & $\begin{array}{l}\text { Definir los usos } \\
\text { del suelo de la } \\
\text { Zona ribereña y } \\
\text { de islas (ZR9). }\end{array}$ \\
\hline
\end{tabular}




\begin{tabular}{|c|c|c|c|}
\hline Municipio & \multicolumn{2}{|c|}{ Neuquén } & Plottier \\
\hline $\begin{array}{l}\text { Ordenanza } \\
\text { municipal }\end{array}$ & 10010 de 2004 & 11795 de 2012 & 3558 de 2014 \\
\hline $\begin{array}{c}\text { Órgano de } \\
\text { gestión }\end{array}$ & $\begin{array}{lr}\text { Cordineu } & \text { S.E., el } \\
\text { Sistema de Planificación } \\
\text { Urbano } & \text { Ambiental } \\
\text { (SPUAM), la } & \text { Unidad de } \\
\text { Coordinación } & \text { de } \\
\text { Planificación } & \text { de } \\
\text { Proyectos } & \text { Urbanos, } \\
\text { Obras Públicas } & \text { y } \\
\text { Planificación y } & \text { la } \\
\text { Unidad Técnica de } \\
\text { Gestión }\end{array}$ & $\begin{array}{l}\text { Secretaría de } \\
\text { Desarrollo Local u } \\
\text { organismo que la } \\
\text { reemplace en el } \\
\text { futuro. }\end{array}$ & $\begin{array}{l}\text { Secretaría de } \\
\text { obras, } \\
\text { planeamiento y } \\
\text { catastro. }\end{array}$ \\
\hline $\begin{array}{l}\text { Modelo de } \\
\text { gestión }\end{array}$ & $\begin{array}{l}\text { Cordineu S.E. concerta } \\
\text { las acciones con todas } \\
\text { las personas físicas, } \\
\text { jurídicas } \\
\text { organizaciones } \\
\text { gubernamentales. }\end{array}$ & 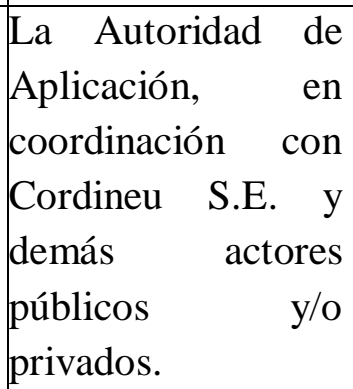 & Sin especificar \\
\hline $\begin{array}{c}\text { Gestión } \\
\text { urbano } \\
\text { ambiental }\end{array}$ & $\begin{array}{l}\text { Sistema de monitoreo y } \\
\text { vigilancia a cargo del } \\
\text { Observatorio Urbano } \\
\text { Ambiental (OUA). }\end{array}$ & Sin especificar & Sin especificar \\
\hline $\begin{array}{c}\text { Usos del } \\
\text { suelo }\end{array}$ & $\begin{array}{l}\text { Zonificación por } \\
\text { distritos (Figura 6): } \\
\text { Distrito 131- Áreas } \\
\text { recreativas, balnearias y } \\
\text { deportivas. Zonas } \\
\text { residenciales } \\
\text { comerciales. } \\
\text { Distrito 132 - Áreas: } \\
\text { administrativa, } \\
\text { comercial y hotelera, }\end{array}$ & Sin especificar & $\begin{array}{l}\text { Toda la zona } \\
\text { tiene el carácter } \\
\text { de área de } \\
\text { protección } \\
\text { especial, para la } \\
\text { preservación de } \\
\text { los atributos } \\
\text { paisajísticos y } \\
\text { ecológicos } \\
\text { existentes. }\end{array}$ \\
\hline
\end{tabular}




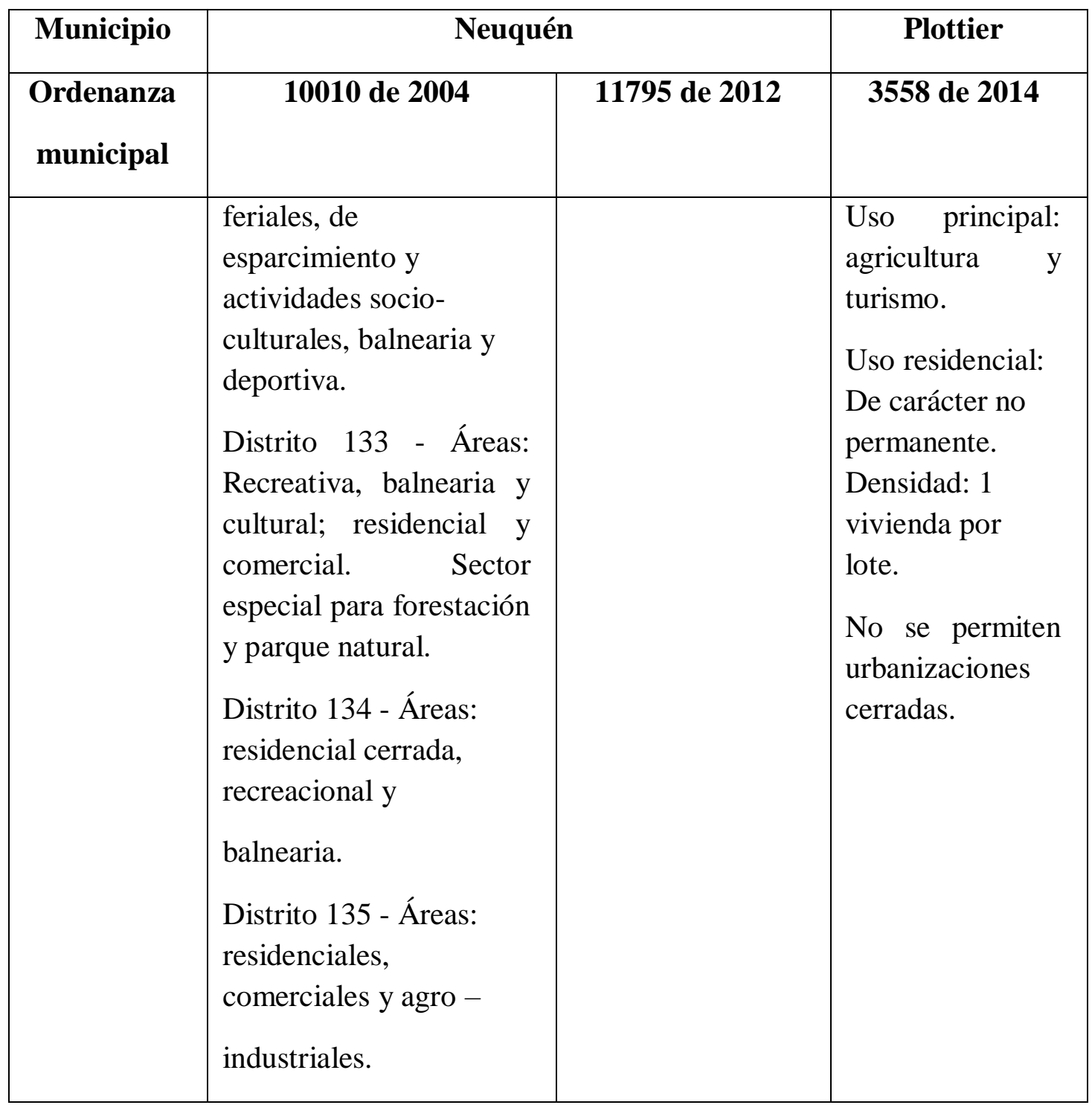

Fuente: elaboración propia. 
Fuente: elaboración propia.

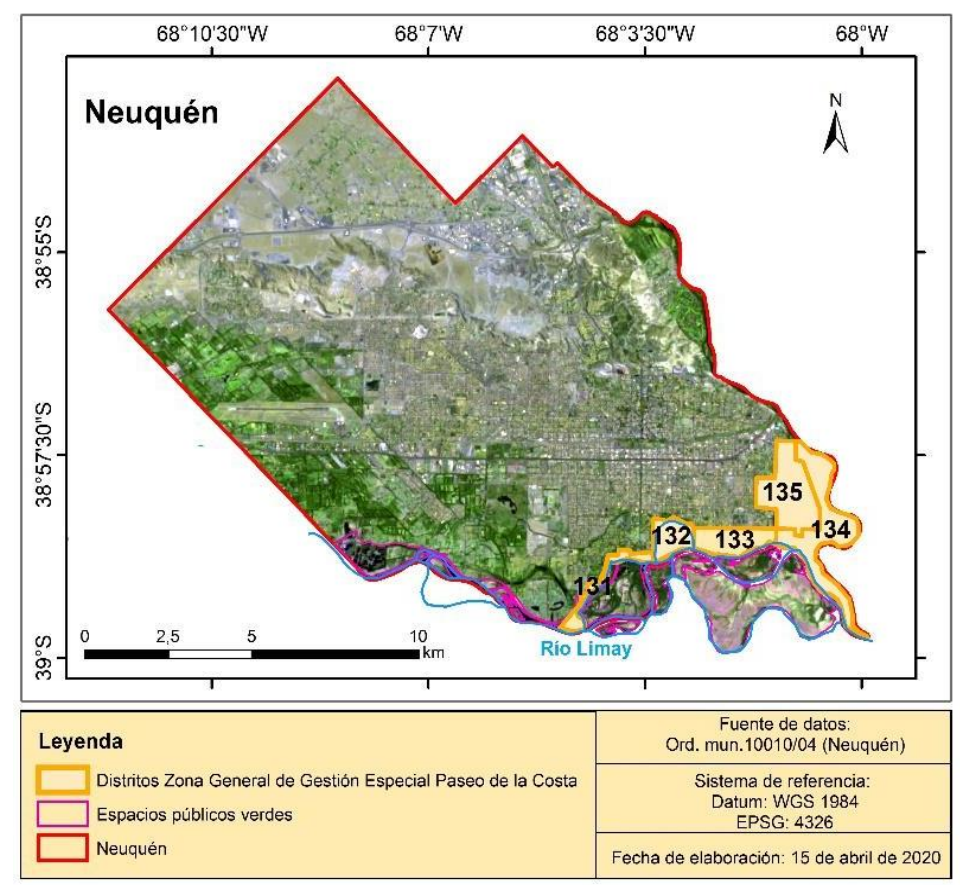

Figura 6. Delimitación de Distritos de la Zona General de Gestión Especial Paseo de la Costa.

Eje 3: Marco normativo de la planificación hídrica en el ordenamiento territorial

Como define el principio rector No. 5 de la política hídrica de la República Argentina, existen actividades que pueden perturbar los recursos hídricos y, en consecuencia, la calidad de vida de la población. Con ello, considera necesario que la dinámica hídrica sea contemplada en el ordenamiento territorial. Esto implica que instituciones ligadas a la gestión del agua participen en la toma de decisiones sobre el uso del territorio y contribuyan en la elaboración de medidas para la mitigación de impactos sobre los recursos hídricos (Consejo Hídrico Federal, 2003). En la Argentina existe una gestión integral de los recursos hídricos que involucra a la Secretaría de Infraestructura y Política Hídrica (Ministerio de Obras Públicas), encargada de diseñar, coordinar e implementar políticas de todo el territorio nacional y al Consejo Hídrico Federal (COHIFE), que trata los aspectos de carácter global, estratégico, interjurisdiccional e internacional de los recursos hídricos y está conformado por Estado Nacional, la Ciudad Autónoma de Buenos Aires y Consejos regionales. En el área de estudio, específicamente, los recursos hídricos son gestionados, a nivel regional, por el Consejo Hídrico Patagónico (COHIPA), y a nivel de local por la Autoridad Interjurisdiccional de los ríos Limay, Neuquén y Negro (AIC), comité de cuencas hídricas.

Dado que el artículo se centra en los espacios públicos sobre las costas ribereñas del río Limay, se abordará en este apartado la normativa en materia de línea de ribera. A nivel nacional, el Código Civil y Comercial Unificado 
(Ley Nacional 26994 de 2014) incorpora nuevos criterios a la planificación hídrica, estableciendo los límites del dominio público y la naturaleza jurídica de las aguas. Define a un río como el agua, las playas y el lecho por donde corre, delimitado por la línea de ribera que fija el promedio de las máximas crecidas ordinarias. Es decir, que el bien de dominio público no es solo el agua que corre por un cauce, sino que abarca también su lecho y playas hasta un cierto límite político (la línea de ribera), lo que implica que la afectación de una de las partes afecta al todo. En base a ello, un informe realizado para el Consejo Hídrico Federal (indica que la línea de ribera fija el límite de lo que es de todos en su integridad, agua y cauce (Del Campo, 2014).

Ahora bien, a partir de la determinación del dominio hídrico público, es facultad de las provincias la fijación de la línea de ribera. La provincia de Neuquén cuenta con dos leyes en relación a la planificación hídrica (Tabla 2).

Tabla 2. Leyes provinciales en relación a la planificación hídrica.

\begin{tabular}{|c|c|c|c|}
\hline Norma & Alcance & $\begin{array}{c}\text { Año de } \\
\text { promulgación }\end{array}$ & Lineamientos \\
\hline $\begin{array}{l}\text { Ley } N^{\circ} \\
273\end{array}$ & Provincial & 1961 & $\begin{array}{l}\text { El Poder Ejecutivo la realización tiene } \\
\text { la responsabilidad de desarrollar los } \\
\text { estudios técnicos necesarios para la } \\
\text { determinación de la línea de ribera legal } \\
\text { de cuerpos de agua. }\end{array}$ \\
\hline $\begin{array}{l}\text { Ley } \mathbf{N}^{\circ} \\
899 \\
\text { Código } \\
\text { de Aguas }\end{array}$ & Provincial & 1975 & $\begin{array}{l}\text { La Dirección de Aguas debe intervenir } \\
\text { en todo lo relativo a obras de cualquier } \\
\text { naturaleza que se ejecuten en cauces y } \\
\text { riberas de los cursos de agua pública. }\end{array}$ \\
\hline
\end{tabular}

Fuente: elaboración propia.

Por la Ley Nacional 23896 de 1990 se aprobó el Tratado de la Creación de la Autoridad Interjurisdiccional de las Cuencas de los ríos Limay, Neuquén y Negro (AIC), cuyo objeto es el manejo armónico, coordinado y racional del recurso, tendiendo a optimizar su uso y con él propender al desarrollo regional. El comité de cuencas fijó 3 líneas para el tramo inferior del río Limay: la línea de ribera: $1290 \mathrm{~m}^{3} / \mathrm{s}$ (máximo caudal autorizado para erogar aguas abajo de la central hidroeléctrica Arroyito), línea de evacuación de crecidas: $1900 \mathrm{~m}^{3} / \mathrm{s}$ (área con alta probabilidad de inundación) y línea de inundación: $2400 \mathrm{~m}^{3} / \mathrm{s}$ (área con probabilidad media y ocasional de inundación) (Departamento Provincial de Aguas, 2007). Sin embargo, si bien es atribución de la AIC analizar y establecer normas o procedimientos para la definición y demarcación de las líneas de ribera, le corresponde al estado provincial definirlas. Por lo tanto, existe 
hoy en la provincia de Neuquén un vacío legal respecto a la línea de ribera del río Limay.

Por su parte, a nivel municipal la ciudad de Neuquén aborda la planificación hídrica dentro del ordenamiento territorial ambiental en dos de sus ordenanzas municipales:

-En el bloque temático No.1 del Código de Planeamiento y Gestión Urbano Ambiental, define como áreas especiales "Zonas con riesgo de inundación". Considera como tales las zonas definidas por la Autoridad Interjurisdiccional de Cuencas de los ríos Limay, Neuquén y Negro (AIC), que comprenden las áreas afectadas por inundaciones con una recurrencia de 10 años y 100 años y anexan un mapa de inundación elaborado por la AIC. A su vez, determina que hasta tanto la autoridad de jurisdicción determine la franja de evacuación de crecidas y las restricciones correspondientes respecto del uso y la ocupación del suelo, las construcciones que no cuenten con la previa autorización expresa del organismo de incumbencia correspondiente (AIC o Recursos Hídricos de la provincia del Neuquén) el peticionante asumirá la total responsabilidad por los daños a su propiedad y a la de terceros que la construcción pudiera provocar.

-La ordenanza municipal 11795 de 2012 establece como una de las tareas del Plan de Consolidación del Paseo Costanero la señalización de las líneas de ribera y de riesgo hídrico conexas (de evacuación de crecidas y de inundación), de acuerdo a lo definido por los organismos técnicos provinciales $\mathrm{y} / \mathrm{o}$ interjurisdiccionales con competencia en la materia. Dicha ordenanza no fue reglamentada.

En cuanto a la ciudad de Plottier, en el Código de Planeamiento Urbano Rural se establece que todo uso de suelo previsto para la zona ribereña y de islas deberá verificar previamente la línea de ribera y solicitar la correspondiente autorización por parte del organismo provincial competente. Sin embargo, no define la línea de ribera a la cual se ajusta dicha normativa. Asimismo, establece que todo uso de suelo tendrá que ceder al dominio público un camino que dará continuidad al paseo costanero. La franja cedida deberá tener un ancho mínimo de 25 metros y será paralela a la línea de inundación. Nuevamente, si bien considera la línea de inundación no la define ni incorpora mapas de zonas bajo riesgo de inundación.

\section{Eje 4: Marco normativo de ordenamiento territorial de bosques nativos}

Los ambientes riparios son muy importantes ya que proveen hábitat a especies vegetales y animales, así como numerosos servicios ecosistémicos, entre ellos uno de los más importantes, actúan como estabilizadores de costas evitando la sedimentación de los cauces (Chauchard et al. 2008) y desbordes ante grandes avenidas.

En el año 2007, a nivel nacional se sancionó la Ley 26331 de 2007 de presupuestos mínimos de protección ambiental para el enriquecimiento, la restauración, conservación, aprovechamiento y manejo sostenible de los bosques nativos. La misma exigía a cada jurisdicción, en un plazo máximo de un año a partir de su sanción, realizar 
el Ordenamiento de los Bosques Nativos existentes en su territorio de acuerdo a los criterios de sustentabilidad establecidos en el anexo de la ley, definiendo diferentes categorías de conservación en función del valor ambiental de las distintas unidades de bosque nativo y de los servicios ambientales que éstos presten. En dicho anexo se reconoce que los corredores boscosos y riparios garantizan la conectividad entre ecoregiones permitiendo el desplazamiento de determinadas especies, por lo que son considerados de importancia para estimar el valor de conservación de un determinado sector y definir los criterios de zonificación.

En la provincia de Neuquén el órgano encargado del OTBN es la Dirección de Gestión de Bosque Nativo (Subsecretaría de Producción del Ministerio de Producción e Industria). La Ley provincial No. 2780 de 2011, establece los principios rectores para el

\section{Marco institucional de los espacios verdes públicos ribereños}

En el apartado anterior se identificaron los actores institucionales implicados en la gestión de los espacios verdes ordenamiento territorial de los bosques nativos. Entre los criterios de zonificación se consideran importantes los bosques en márgenes de cursos de agua, espejos de agua y humedales. Con ello, los bosques que se encuentren en áreas de cincuenta (50) metros en márgenes de curso de agua medidos desde la línea de ribera serán clasificados en Categoría I (rojo) de conservación.

En el Área Metropolitana de Neuquén el valle fluvial del río Limay representa una isla biogeográfica con características de corredor fluvial. En base a los criterios de zonificación de la Ley No. 2780 de 2011, se entiende que este bosque ripario es de categoría I de conservación. Sin embargo, en el mapa de ordenamiento territorial de bosques nativos en la provincia estos ambientes ribereños no están siquiera categorizados como bosques. Esto es consecuencia de la inexistencia de líneas de riberas legales a nivel provincial.

públicos en función de los cuatro ejes de análisis. En la Figura 7 se resume el marco institucional. Se observa que el eje Ordenamiento Territorial Ambiental es el de mayor injerencia institucional, mientras que el eje de OTBN es el eje que involucra menor complejidad. 
Fuente: elaboración propia.

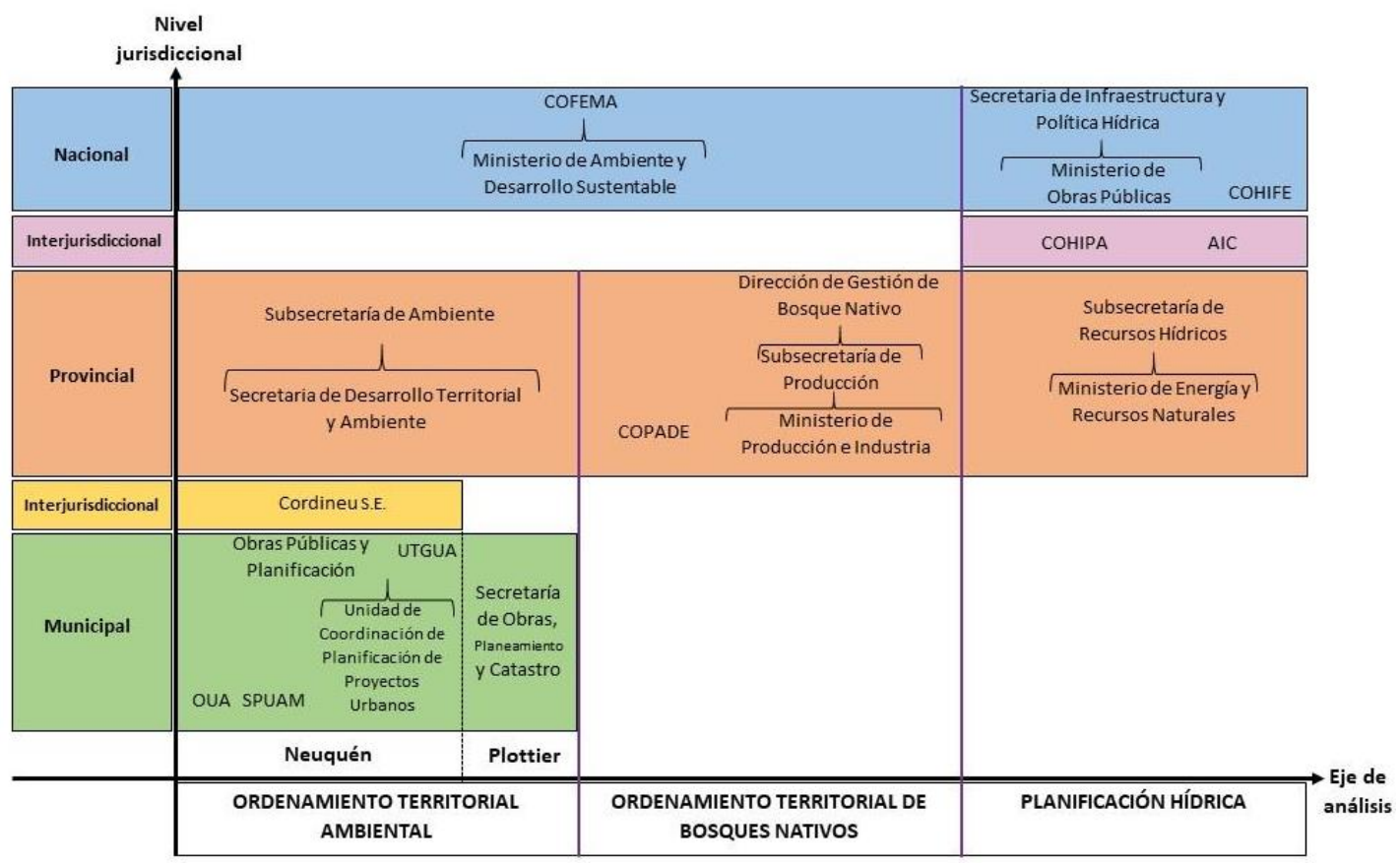

Figura 7. Mapa de instituciones.

\section{Análisis comparativo crítico entre} los marcos de Neuquén y Plottier La revisión del marco normativoinstitucional que rigió y rige los espacios públicos verdes ubicados sobre la costa del tramo inferior del río Limay, en las ciudades de Plottier y Neuquén, fue realizada en torno a 4 ejes: la jurisdicción de los espacios verdes; el ordenamiento territorial ambiental; la planificación hídrica y el Ordenamiento Territorial de Bosques Nativos (OTBN) provincial. Para cada uno de los cuales se pudo dar cuenta de las siguientes premisas:

1. La jurisdicción de los espacios verdes es municipal, pero en Neuquén el manejo de un sector del área ribereña le corresponde a una sociedad del Estado (Cordineu S.E.);

2. El ordenamiento territorial ambiental es considerado por ambas ciudades, sin embargo, la ciudad de Neuquén cuenta con una mayor trayectoria en planeamiento $\mathrm{y}$ posee ordenanzas específicas para los espacios costeros;

3. La planificación hídrica, en cuanto a definición de líneas de ribera, es ambigua en ambas ciudades;

4. Los bosques ribereños no están categorizados dentro del Ordenamiento Territorial de Bosques Nativos (OTBN) provincial.

La provincia de Neuquén y en particular las ciudades del área metropolitana, tienen un importante desarrollo en materia de ordenamiento territorial, incluso mayor que a nivel nacional. Al respecto, el análisis del marco normativo de la ciudad de Neuquén permitió delimitar tres etapas respecto a la evolución de los espacios verdes públicos ribereños en el ordenamiento territorial histórico: Una primera etapa en la que los espacios verdes costeros no 
se consideraban en el ordenamiento territorial (década 1960-1970); Una segunda etapa en la que los espacios verdes costeros se incorporaron a la planificación del ejido como áreas de esparcimiento y reserva (décadas 19701990); Una tercera etapa en la que se reconoce una diversificación de los usos del suelo en los espacios verdes públicos sobre la costa (desde la década de 1990 hasta la actualidad). Asimismo, se pudieron observar ciertas particularidades que diferencian a la ciudad de Neuquén del resto de las localidades que conforman el Área Metropolitana de Neuquén:

-La metrópolis, en contraposición con la ciudad de Plottier, cuenta con un marco normativo-institucional más magno y con una gran trayectoria histórica desde el ordenamiento territorial. A su vez, al comparar ambos marcos normativoinstitucionales es evidente que los frentes de agua representan distintos significados en ambas ciudades.

-No obstante, en este artículo se expone que el número de ordenanzas municipales o la complejidad institucional no implican la reducción o inexistencia de vulnerabilidad normativa-institucional. Este caso es un claro ejemplo, ya que en ambas ciudades no existen claramente líneas de ribera definidas, lo que conlleva a, por un lado, no aplicar la Ley provincial 2780 de 2011 de ordenamiento territorial de bosques nativos en la región, y por otro lado desarrollar proyectos de gran envergadura en áreas expuestas al riesgo de inundación.

-En este sentido, el código de planeamiento urbano de Plottier, en comparación con el de Neuquén, tiene un carácter más conservacionista y proteccionista en las áreas de parques ribereños e islas. No obstante, pese a ello no especifica cuáles son las medidas o tareas para lograr dichos objetivos.

-La revisión de un marco normativoinstitucional no responde a criterios cuantitativos, sino cualitativos. Ejemplo de ello es que, en la ciudad de Neuquén a diferencia de Plottier, se cuenta con una ordenanza particular para espacios verdes públicos sobre la ribera del río Limay. Sin embargo, esta ordenanza permite flexibilidad en intervenciones en el bosque ribereño, cuestión que en la ciudad de Plottier, con un código de planeamiento mucho más laxo no ocurren.

-Por otra parte, en la región, la existencia de un marco normativo no garantiza su cumplimiento, ya que como ocurre en Plottier, áreas definidas como protegidas son intervenidas con usos de suelo incompatibles según el código de planeamiento urbano. Numerosos ejemplos se presentan también en la ciudad de Neuquén.

Con base en lo anterior, la calidad de los espacios verdes públicos sobre la costa del río Limay en el área metropolitana de Neuquén, la vulnerabilidad física del bosque ribereño y los riesgos a la población asociados, responden a decisiones y acciones políticas, que tienen poca relación con la cantidad de ordenanzas municipales promulgadas sino con la calidad de las mismas. En concordancia con lo expresado por Sevilla Buitrafo (2014, en Fernández Romero, 2019): 
Al analizar de manera contextualizada los procesos de creación de espacios verdes, queda en evidencia que los objetivos de los actores involucrados no se limitan a la preservación de entornos con vegetación ni a la provisión de áreas de esparcimiento, sino que se traslucen fines más amplios vinculados con un proyecto de espacio urbano o periurbano $y$, por ende, con un proyecto de sociedad. (p. 3)

\section{Conclusiones}

El análisis normativo-institucional permitió dar cuenta de la complejidad de la gestión de los espacios verdes públicos ribereños del AMN, relacionada con una superposición de zonas de diversas categorías (áreas costeras, bosques riparios, espacios verdes, zonas de gestión urbanas especiales). Esto quedó evidenciado en el grueso marco normativo $\mathrm{e}$ institucional vigente en los diferentes niveles jurisdiccionales involucrados (municipales, provincial, regional y nacional). Por otra parte, la existencia de un mayor número de normativas relacionadas con el Ordenamiento Territorial Ambiental local, por sobre las

8. Referencias bibliográficas

Banco Interamericano de Desarrollo. (2015). Gestión Urbana, Asociaciones Público Privadas y Captación de Plusvalías: El caso de la recuperación del frente costero del río Paraná en la Ciudad de Rosario, Argentina. coherentes con la planificación hídrica y el OTBN, demuestran la necesidad de incrementar la articulación entre instituciones abocadas a la gestión del ecosistema urbano, en este caso el espacio verde público ribereño, y de las otras categorías ecosistémicas (costera y bosque). A su vez, en el análisis conjunto, se observó que la calidad de los espacios verdes abordados, y su sustentabilidad desde una dimensión jurídica, no responden a criterios cuantitativos sino cualitativos.

En un contexto internacional en el que los frentes de agua se constituyen en una categoría emergente de espacio público, se incrementa la complejidad, tanto desde el ámbito físico como desde el jurídico-administrativo. Resulta fundamental, entonces, re-pensar las formas de gestionar los espacios verdes desde una visión sistémica. Para tal fin, y en línea con lo realizado en este artículo para la región del AMN, es preciso identificar y definir para cada región específica los ejes de abordaje adecuados, con el objetivo de lograr una gobernanza integral y cooperativa, ya que es la esfera que "debe responder a los contextos físicos, sociales, políticos e institucionales específicos de cada espacio" (Glückler et al., 2019, p. 7).

Editorial

BID. https://bit.ly/2IlFOc0

Bendini, M., y Steimbreger, N. (2007). Nuevos espacios productivos en la Patagonia: reestructuración social de una cadena tradicional agrícola. Pampa, 1(3), 145-164.

Boggi, R., y López, A. (12 de octubre de 2019). Cómo empezó Pechi, en el 
verano del 2000. Diariamente Neuquén.

https://www.diariamenteneuque n.com.ar/V3.0/2019/10/12/como -empezo-pechi-en-el-verano-del2000/

Borja, J., y Muxí, Z. (2003). El espacio público: ciudad y ciudadanía. Barcelona: Electa

Castillo, G. (2013). Indicadores ambientales de espacio público en Bogotá (Tesis de Maestría, Universitat Politécnica de Catalunya).

https://upcommons.upc.edu/bitst ream/handle/2099.1/20822/Mem \% $3 \%$ B2ria\%20\%20Ginna\%20Alexandra\%20C ASTILLO.pdf

Ceballos Guerra, J. C. (2013). En el contexto de la city marketing: mutaciones en las formas de habitar de los espacios cívicos del centro urbano. XV Encuentro Enapur: Desenvolvimento, Planeajamento e Governanca. Río de Janeiro, Brasil.

Chauchard, L., Bava, J., Laclau, P., Loguercio, G., Pantaenius, P., y Rusch, V. (2008). Manual para las buenas prácticas forestales en bosques nativos de Norpatagonia. Editorial CIEFAP http://www.ciefap.org.ar/docum entos/Buenas Practicas Forestal es AndinoPatagonico.pdf

Chavoya Gama, J. I. (2-4 de octubre de 2013). El manejo de grandes parques urbanos en la ciudad: apuntes sobre politicas públicas ambientales; el estero El Salado en Puerto Vallarta. Internacional Conference Virtual City and
Territory. "9 Congresso Cittá e Territorio Virtuale, (pp. 11431162). Universitá degli Studi Roma Tre, Roma, Italia.

Consejo Hídrico Federal. (2003). Principios rectores de política hídrica de la República. Argentina. Buenos Aires. http://www.cohife.org/advf/docu mentos/2015/10/561b1c0da79ae .pdf

Converti, R., y De Marco, F. (2007). Arquitectura. Urbanismo. Argentina. Recuperado de: https://arqa.com/arquitectura/urb anismo/ribera-urbana-ciudad-deneuquen.html

COPADE. (2019). Visión Neuquén 2030. Provincia de Neuquén. https://www.copade.gob.ar/Arch ivos/Libro\%20Visi\%C3\%B3n\% 202030.pdf

Datri, L. A., y Maddio, R. (2010). Geometrías fluviales en la definición del paisaje de la colonia Valentina Sur (Neuquén) y Balsa Las Perlas (Río Negro). Calidad de vida- Universidad de Flores, 1(5), 141-157.

Del Campo, C. (2014). Informe Código Civil y Comercial Unificado 2014-2015. Las Aguas en el nuevo Código Civil y Comercial Unificado. Buenos Aires. http://www.cohife.org/advf/docu mentos/2015/10/562fd60c443cd. pdf

Departamento Provincial de Aguas. (2007). Avances en la definición de líneas de riesgo hídrico en la provincia de Río Negro [Diapositiva de Powerpoint]. Jornada Nacional de Líneas de Riesgo Hídrico. San Carlos de 
Bariloche. Recuperado de: http://www.bibliotecacpa.org.ar/ greenstone/collect/otragr/index/a ssoc/HASH0158.dir/doc.pdf

Dirección General de Arquitectura y Urbanismo. (1992). Áreas recreativas-turísticas de los ríos Limay y Neuquén. Usos y restricciones. Neuquén.

Fernández Romero, F. (2019). Espacios verdes ¿Para qué y para quiénes? Territorialidades en disputa en el Área Metropolitana de Buenos Aires (1944-2016). Estudios Socioterritoriales, 25, 1-16.

Galacho Jiménez, F. B. (2002). Los usos del suelo en el espacio costero de la provincia de Málaga basados en un modelo de desarrollo urbano-turístico con importantes consecuencias ambientales. Baetica. Estudios de Arte, Geografía e Historia, 24, 21-61.

García, S., y Guerrero, M. (2006). Indicadores de sustentabilidad ambiental en la gestión de espacios verdes. Parque urbano Monte Calvario, Tandil, Argentina. Revista de Geografía Norte Grande, 35, 45-57.

Garriz, J. E., y Schroeder, R. V. (2016). Reflexiones sobre los frentes de agua en el contexto de las intervenciones urbanas. Huellas, 20, 17-34.

Gastaldi, F., y Camerin, F. (2015). La regeneración urbana y los grandes eventos en Génova en el período 1992-2004. Revista de Estudios Urbanos y Ciencias Sociales, 5(1), 71-88.

Glückler, J., Rehner, J., y Handke, M. (2019). Gobernanza, redes y territorio. Revista de Geografía Norte Grande, 74, 5-20

Hernández Sampieri, R., Fernández Collado, C., y Baptista Lucio, P. (2014). Metodología de la investigación. México: McGraw Hill.

Landriscini, G., Domeett, G., y Rivero, I. (2014). Neuquén, ciudad intermedia $\mathrm{y}$ nodo regional. Algunas evidencias de la dinámica económica y la centralidad urbana. Pilquen, 17(1), 1-15.

Lozano Leal, I. M., Vargas Hernández, G., y Murillo Hernández, M. Á. (2016). Análisis de la implementación de indicadores de turismo sustentables en el municipio de Zipaquirá Cundinamarca. Revista digital Perfiles libertadores, 1, 38-54.

Ley Nacional $N^{\circ}$ 23896/1990, de 2 de noviembre de 1990, por la cual se aprueba el tratado de la creación de la Autoridad Interjurisdiccional de las Cuencas de los ríos Limay, Neuquén y Negro. En Boletín Oficial de la República Argentina, Buenos Aires, Argentina.

Ley Nacional $\mathrm{N}^{\circ}$ 25675/2002, de 28 de noviembre de 2002, por la cual se establecen los presupuestos mínimos para el logro de una gestión sustentable y adecuada del ambiente. En Boletín Oficial de la República Argentina, Buenos Aires, Argentina.

Ley Nacional $\mathrm{N}^{\circ}$ 26331/2007, de 26 de diciembre de 2007, por la cual se establecen los presupuestos 
mínimos de protección ambiental de los bosques nativos. En Boletín Oficial de la República Argentina, Buenos Aires, Argentina.

Ley Nacional $N^{\circ}$ 26994/2014, de 8 de octubre de 2014, por la cual se aprueba el Código Civil y Comercial Unificado de la Nación. En Boletín oficial de la República Argentina, Buenos Aires, Argentina.

Ley Provincial N 263/2003 TO 669, de 29 de octubre de 2003, la cual establece el código de tierras fiscales. En Boletín Oficial de la provincia de Neuquén, Neuquén, Argentina.

Ley Provincial $\mathrm{N}^{\circ} 273 / 1961$ de 4 de diciembre de 1961, por la cual se define el camino de sirgas en la provincia de Neuquén. En Boletín Oficial de la provincia de Neuquén, Neuquén, Argentina.

Ley Provincial N ${ }^{\circ} 899 / 1975$, de 24 de octubre de 1975, por la cual se aprueba el Código de Aguas. En Boletín Oficial de la provincia de Neuquén, Neuquén, Argentina.

Ley Provincial N 1875/1998, TO 2267, de 27 de noviembre de 1998, por la cual se definen los principios rectores para la preservación, conservación, defensa y mejoramiento del ambiente. En Boletín Oficial de la provincia de Neuquén, Neuquén, Argentina.

Ley Provincial $N^{\circ}$ 2420/2002, de 5 de diciembre de 2002, la cual establece la transferencia provincial de todos los inmuebles de espacios verdes a las jurisdicciones municipales. En
Boletín Oficial de la provincia de Neuquén, Neuquén, Argentina.

Ley Provincial N ${ }^{\circ}$ 2780/2011, de 22 de diciembre de 2011, la cual establece los principios rectores del Ordenamiento Territorial de Bosque Nativo en la provincia de Neuquén. En Boletín Oficial de la provincia de Neuquén, Neuquén, Argentina.

Lopez, M., Datri, L., Miranda, E., Boyero, L., y Faggi, A. (2019). Álamos sensores de cambios en el paisaje fluvial del río Limay. Revista de la Asociación Argentina de Ecología de Paisajes, 9(1), 77-80.

Maldonado Saravino, T. P (2016). Producción de territorios: entre la multifuncionalidad $y$ Multiterritorialidad en la plaza de ponchos De Otavalo (Tesis de Maestría, Facultad Latinoamericana de Ciencias Sociales)

https://repositorio.flacsoandes.e du.ec/bitstream/10469/9031/1/T FLACSO-2016TPMS.pdf

Morello, J. H. (1995). Grandes Ecosistemas de Suramérica. En G. Gallopín (Comp.), El Futuro Ecológico de un Continente (pp. 21-100). Editorial del a Universidad de las Naciones Unidas y Fondo de Cultura Económica.

Nogué, J. (2006) Geografía Política. En D. Hiernaux y A. Lindón. Tratado de Geografía Humana (pp. 202-2019). Ed. Anthropos

Ordenanza municipal No.8201/1998, de 10 de julio de 1998, por la cual se aprueba el actual código de planeamiento y gestión urbano 
ambiental. En Digesto Concejo Deliberante de la ciudad de Neuquén, Neuquén, Argentina.

Ordenanza municipal No.8976/2000, de

22 de diciembre de 2000, por la cual se crea CORDINEU S.E. En Digesto Concejo Deliberante de la ciudad de Neuquén, Neuquén, Argentina.

Ordenanza municipal No.10010/2004, de 8 de julio de 2004, por la cual se aprueba la norma reguladora básica urbana ambiental de la zona de gestión especial Paseo de la Costa. En Digesto Concejo Deliberante de la ciudad de Neuquén, Neuquén, Argentina.

Ordenanza municipal No.10702/2006, de 22 de diciembre de 2006, la cual modifica el artículo No.2 de la ordenanza No.8976 de 2000. En Digesto Concejo Deliberante de la ciudad de Neuquén, Neuquén, Argentina.

Ordenanza municipal No.11795/2012, de 20 de mayo de 2012, por la cual se crea el Plan de Consolidación Costera del Paseo de la Costa. En Digesto Concejo Deliberante de la ciudad de Neuquén, Neuquén, Argentina.

Ordenanza municipal No.12849/2013, de 14 de noviembre de 2013, la cual habilita el balneario Valentina Brun de Duclout. En Digesto Concejo Deliberante de la ciudad de Neuquén, Neuquén, Argentina.

Ordenanza municipal No.12982/2014, de 10 de abril de 2014, modifica artículos de la ordenanza No.10010 de 2004. En Digesto Concejo Deliberante de la ciudad de Neuquén, Neuquén, Argentina.

Ordenanza municipal No.13587/2016, de 1 de diciembre de 2016, la cual designa el nombre del balneario Valentina Brun De Duclout. En Digesto Concejo Deliberante de la ciudad de Neuquén, Neuquén, Argentina.

Ordenanza municipal No.13607/2016, de 15 de diciembre de 2016, la cual crea el Parque Limay. En Digesto Concejo Deliberante de la ciudad de Neuquén, Neuquén.

Ordenanza Municipal N³558/2014, de 5 de junio de 2014, la cual aprueba el actual código de planeamiento urbano rural. En Digesto Concejo Deliberante de la ciudad de Plottier, Neuquén, Argentina.

Orellana, A. G., Díaz Zamora, M. M. y Fierro Page, M. T. (2016). De ciudad mediterránea a metrópolis costera, el caso de Gran La Serena. Revista Urbano,33, 3043.

Pavia, R. (2011). Waterfront. Áreas estratégicas de las ciudades portuarias. Portus, 22, 4-15.

Pérez, G. G. (2018). La conurbación en torno a la ciudad de Neuquén. Perspectiva regional y aportes para el ordenamiento territorial [Tesis de Doctorado, Universidad Nacional de La Plata]. http://www.memoria.fahce.unlp. edu.ar/tesis/te.1583/te.1583.pdf

Pinzón Botero, M. V. y Echeverri Álvarez, I. C. (2012). La sostenibilidad ambiental regional: una propuesta 
metodológica para su estudio más allá de la ecología urbana. Luna Azul, 34, 131-147.

Porco, V. A. (2017). Crecimiento urbano en la periferia de la ciudad de Neuquén: zonas de inestabilidad en ladera y pedimento. En S. Roca, y A. Manacorda, Ambiente y salud en un área periurbana de Neuquén (pp. 235-259). Neuquén: Educo- Editorial de la Universidad Nacional del Comahue.

Programa de Desarrollo de Áreas Metropolitanas del Interior. (2014). Agenda de prioridades. Área metropolitana de Neuquén. Neuquén.

https://www.upefe.gob.ar/wpcontent/uploads/agendaprioridades-metropolitananeuquen-01-15.pdf

Quintero, S. (2007). Territorio, gobierno y gestión. En M. V. Fernández Caso, y R. Geografía, nuevos temas, nuevas preguntas. Editorial Biblos.

Raimondo, A. M. (2010). Propuesta para una definición de la franja costera, usos y actividades en la costa de Comodoro Rivadavia Chubut. Patagonia Argentina. Párrafos Geográficos, 9(1), pp. 66-100

Salina Chávez, E., Navarro Jurado, E., Echarri Chávez, M., y La O Osorio, J. A. (2008). Metodologías para la evolución de la sustentabilidad territorial: el uso de indicadores en destinos turísticos de Cuba. Boletín de la R.S.G., 144(1), 75-102.

Sociedad Argentina de Planificación Territorial (SAPLAT). (2019).
Bases para una agenda nacional de planificación territorial. Buenos Aires. http://www.saplat.website/PDF/ SAPLAT_2019_4x4.pdf

Sosa Ferreira, A. P., y Jiménez Martínez, A. (2012). La política turística en Cancún (México) como destino turístico maduro ¿Renovar o aplicar? En J. F. Vera Rebollo y I. Rodríguez Sánchez, Renovación y reestructuración de destinos turísticos en áreas costeras (pp. 71-93). Valencia: Universidad de Valencia.

Talesnik, D., y Gutiérrez, A. (2002). Transformaciones de frentes de agua: la forma urbana como producto estándar. EURE (Santiago), 28(84), 21-31.

Tapella, E. (2007) El mapeo de Actores Claves.

Córdoba. https://planificacionsocialunsj.fil es.wordpress.com/2011/09/quc3 a9-es-el-mapeo-de-actorestapella1.pdf

United Nations General Assembly (2015) Transforming our world: the 2030 agenda for sustainable development. (Transformando nuestro mundo: la agenda 2030 para el desarrollo sostenible). United Nations, Geneva

Wertheimer, M. C. (2018). Renovación urbana y conflictos territoriales en las costas metropolitanas del Río de la Plata: los casos de Quilmes, Avellaneda y Vicente López. Estudios del hábitat, 16(2), p. 1-14 